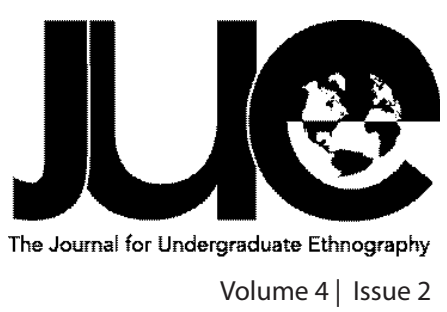

\title{
Gender Maneuvering over Coffee: Doing Gender through Displays of Hegemonic Masculinity and Alternative Femininity
}

\author{
Jedidiah McClean
}

Portland State University, jmcclean@pdx.edu

\section{ABSTRACT}

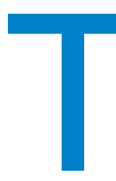

his research examines how individuals "do gender" in an urban coffee shop by performing gender maneuvering strategies in order to gain masculine cultural capital typically accessed through displays of hegemonic masculinity. This participant ethnography was conducted in a corporate coffee franchise over the course of eight weeks, to observe gendered interactions in a public space. Observations were made of customer and barista socialization in the store, where gender displays were maneuvered through social artifacts such as clothing and hairstyles; as well as gendered social transactions such as conversational styles and heteronormative social customs. Research findings suggest that both masculine and feminine social actors adopted traits of hegemonic masculinity in order to gain a dominant social position during an interaction, while a few chose to display an alternative form of femininity to achieve the same goal. Gender maneuvering strategies in these interactions were identified by analyzing variations in patron's gender displays. This study examines how individuals do gender within mixed-gender dyads, feminine dyads, masculine dyads, and through displays of alternative femininities.

Keywords: doing gender, hegemonic masculinity, alternative femininity, gender maneuvering, masculine cultural capital 
INTRODUCTION

Gender displays are ever shifting social constructions, created and reified through social transactions by multiple actors located within specific organizational contexts. The "coffee date" is one specific social transaction in which different gender displays may interact to create a myriad of gendered social dynamics. These dynamics determine who is dominant, having power and privilege in society; creating and perpetuating social inequalities. West and Zimmerman's (1987) theory of "doing gender" can be posited as a process of creating social inequalities, based on differentiating between boys/men and girls/women in ways that are "not natural, essential, or biological" (137). The reciprocal relationship between the social construction and transactional reification of gender disparities in society creates and sustains the hierarchy of masculine dominance over femininity. West and Zimmerman also contend that these gender differences are a product of gendered social transactions that ascribe asymmetrical status between two individuals, creating a disparate gender binary. The objective that such a gender binary most readily serves is the inequitable "allocation" of resources, power, and privilege in society (West and Zimmerman 1987, 143), elevating the dominant form of masculinity above feminine gender expressions. The dominance of a single masculine identity also negatively impacts the expressions of male identified individuals who may be considered less masculine; i.e. homosexuals, transmen, men of color, and men of lower socioeconomic status. In this study, doing gender is used as a theoretical foundation to explain how individuals negotiate gender disparities in an urban coffee shop located in a Northwestern city in the Unites States. The coffee house setting was specifically chosen for this study as patrons on coffee dates are often less distracted by activities like eating, and socialization may occur freely in this caffeine energized environment. 


\section{LITERATURE REVIEW}

To properly analyze the specific gendered transactions occurring between individuals frequenting the shop on coffee dates, it is important to first understand the dynamics that exist when two individuals interact. The sociological use of the term "dyad" in this study is intended to describe the unique relationship created between two individuals, persisting over time, where "face-to-face relations" establish a discernable pattern of interaction (Becker and Useem 1942, 13). The dyad is socially constructed when each individual performs gendered social transactions in cooperation with the other. These transactions are established through early gendered socialization processes which are viewed as "natural", but which serve to create a gendered hierarchy. Within the context of the dyad, regardless of the biological sex of either member, individuals who wish to gain access to social resources and power may perform their "gender display" (Goffman 1976) according to a heteronormative binary, derived from the socially constructed ideals of "hegemonic masculinity" and "emphasized femininity" (Connell 1987). Furthermore, heteronormativity promotes a worldview in which heterosexuality is the preferred sexual identity of individuals, honoring heterosexual couples by positing them as the normal composition for romantic dyads in society. Hegemonic masculinity is thus accorded the highest status in society and social actors displaying this gender are afforded the most access to social resources and privileged positions. Those who display emphasized femininity through the socially idealized characteristics of "compliance, nurturance, and empathy" (Connell 1987,188 ) are seen as being the ideal heterosexual partners of those displaying hegemonic masculinity. Within this system of inequality, individuals with a feminine gender display therefore typically gain access to socially protected resources through their masculine partners.

Goffman (1976, 69-70) described gender displays as behavioral exchanges where the "absence of symmetry" creates a hierarchy of dominance and deference. The observations in this study establish that these status inequalities exist in most dyadic relationships, regardless of the gender composition. Yet dominance is often negotiated through gendered social transactions, in order to gain "masculine cultural capital" (Bourdieu 1984); which can be described as social power and privilege used by those in the dominant gender group to negotiate for resources and position through symbolic social transactions.
It can also be accessed by members of a subordinate group as a "symbolic currency used to elevate their social standing" within the context of a dyad (Ocampo 2012, 449). Masculine cultural capital allows subordinate group members access to power and resources normally out of reach. An individual's gender identity is socially constructed beginning at birth, based on their assigned sex category and reified throughout their lifetime by the performance of a gender role. Through a gender display individuals are able to secure their gender's allocation of social resources. In the quest for resources, power, and prestige beyond the patriarchally determined level of one's gender status; those who have historically been denied equal rights in society will often adopt behaviors ascribed to hegemonic masculinity, in order to access the power of masculine cultural capital.

In dyadic relationships, whether romantic, social, or business oriented, the gender display being enacted by either member can determine who has the dominant and deferent positions in an interaction. This can have serious implications for the allocation of resources or decision making processes, depending on the gender composition of the dyad. It is the proposal of this study that in any of these dyads, one member may enact a display of hegemonic masculinity to assert their position as dominant and the other may assume the emphasized feminine position of deference. Where these gender displays do not conform to perceived sex categories, it is the proposal of this study that individuals may be performing the social transaction of "gender maneuvering" (Schippers 2002) to increase their social power within the dyad, gaining access to masculine cultural capital. Gender maneuvering can be described as gendered symbolic transactions that signify or imply the actor's power and privilege within the dyad, placing them in a dominant or deferent position. Gender maneuvering in this case attempts to challenge the relationships between masculinity and femininity, allowing individuals to access the cultural capital primarily ascribed to a masculine gender display. This can be achieved by "detach[ing] masculinity" from a male body, thereby doing gender through temporary displays of hegemonic masculinity (Pascoe 2011, 116).

Finally, another method for accessing masculine cultural capital can be attained through the display of an "alternative femininity" (Schippers 2002; Schippers 2007). Alternative femininities may attempt to challenge the hegemonic stratification of gender displays by intentionally replacing them with ones 
"that do not articulate a complementary relation of dominance and subordination between men and women" (Schippers 2007; Finely 2010, 362). These displays appear to be an attempt to "redo gender" (Connell 2010). Such non-submissive forms of femininity seek to undermine the oppressive traits of hegemonic masculinity identified by some researchers as "dominance", "virility", and "lack of emotion" (Wood 2000; Lodge and Umberson 2012).

\section{METHODS}

The observational field site for this participant ethnography (Emerson et al. 2011) was a corporate coffee franchise (herein referred to as "Coffee Corps") located in an affluent urban neighborhood in the Northwestern region of the Unites States. This store was frequented by a myriad of individuals, dyads, and larger groups consuming coffee and participating in gendered social transactions. This study primarily focused on the interactions of dyads frequenting the shop, as well as several unique women, in order to observe how gender displays were maneuvered to gain cultural capital, typically through displays of hegemonic masculinity.

The site itself is located on the corner of a busy intersection and observations were typically made from a table in a cluster of two-seat options making it ideal for observing dyadic interactions. The store is large and roughly square, with an entrance directly on the corner of the building, allowing for access from multiple directions. Patrons entering from the corner are forced to walk around the seating area, which gave plenty of time to observe style of dress, posture, facial expression, and many other gendered traits. The coffee bar ordering station had two registers with a small counter space between them. To the right of the registers was the barista station and at the end was the pick-up counter where the baristas announced prepared drink or food items. Generally the store smelled only mildly of coffee, atypical of such a setting. The free wireless internet, combined with a plethora of electrical outlets in the store, seemed to be a big incentive for anyone attempting to be studious. I typically dressed in jeans and a flannel button up or a sweater. I selfidentify as male and heterosexual, and have a masculine gender presentation, and dress in a style typical of this area. Therefore I believe I passed as a typical student customer.

This study was conducted using participant ethnography, wherein customer's gendered interactions while purchasing and drinking coffee were observed. A total of 20 observational hours were conducted over the course of 10 sessions, at a coffee bar located in an active shopping and dining district of the city. Observational sessions were conducted at an early hour once a week when there was a high probability of observing pairs of customers engaging in gendered dyadic interactions. Special attention was paid to the perceived gender display of each member of these dyads and to the verbal and nonverbal forms of communication potentially being utilized to attain a position of dominance or deference. The doing of gender in this field site was noted through behaviors and traits ascribed to masculinity and femininity; such as posture, tone and volume of voice, content of conversations, eye contact, body position, expressiveness, display of SES, and style of hair, clothing, and makeup when applicable.

All gendered interactions during these periods were recorded through ethnographic field notes and all data collected during the course of this study was purely observational. At the end of each session, a full transcription of observational findings was immediately recorded, either at the coffee shop or upon returning home. All personal speculations and theorizing were constrained to "asides" and "commentaries" in an attempt to preserve the authenticity of observations (Emerson et al. 2011).

\section{LIMITATIONS}

The obvious limitation for this study is that of conducting participant ethnography without any additional data collection methods. The absence of a subject's self-perception of their gender maneuvering strategies leaves results lacking in external applicability. As most of the observed individuals employed heteronormative gender displays and the sample is small results cannot be generalized beyond the scope of this study. Also the patrons frequenting this shop were mostly white, nonHispanic; although Hispanic individuals appeared to comprise the largest minority group represented in this store's patronage. Consequently the intersectionality of race and gender cannot be factored into this analysis of gender maneuvering strategies. Future studies in this area could attempt to explain how gender intersects with race, as well as with sexuality and class, to influence how individuals perform gender maneuvering within the context of the dyad.

Observations of the sex, sexuality, and gender identity of 
the patrons during this study were filtered through the lens of my male, masculine, and heterosexual self-expressions. Thus descriptions of individuals' gender displays are based on my perception of these identities, as they are being performed through dyadic and social transactions. Utilizing interview data to ascertain self-descriptions of patrons' gender expressions could have further legitimized findings. A more accessible and in-depth ethnographic study of dyadic transactions could also lead to verifying observations about individuals gender expressions, which could be beneficial in verifying this study's results. Finally, future studies should include transgender expressions, as well as the gender displays of individuals with disabilities to move beyond the narrow scope of this study's findings.
Overall my observations confirmed my assumption that the majority of customers frequenting Coffee Corps displayed either hegemonic masculinity or emphasized femininity (Connell 1987). However, the focus of my research was to identify gender maneuvering strategies (Schippers 2002), therefore the results of this study suggest that many individuals performed gender displays which differed from their perceived primary gender expression to varying degrees. These displays often seemed to reify hegemonic masculinity when enacted by individuals displaying an overall masculine or feminine gender display, and conversely a few individuals appeared to challenge the gender hierarchy through a display of an alternative femininity. Examples of gender maneuvering were often observed in the interactions of mixed-gender dyads in which individuals attempted to access masculine cultural capital through a temporary display of hegemonic masculinity or emphasized femininity. 


\section{GENDER MANEUVERING IN MIXED-GENDER DYADS}

Within the framework of hegemonic masculinity and emphasized femininity, I observed that most of the dyadic transactions taking place in the shop appeared to have a heteronormative composition, occurring between two heterosexual individuals of normatively opposite genders. In the context of individual deviations from normative gender performances, this section will focus primarily on individuals performing gender maneuvering strategies within heteronormative dyads, in order to access masculine cultural capital.

Over the course of my observational period there was one blonde woman who appeared in the shop during each session. My first encounter with her was as part of a small group seated at a large table. I will return to this interaction in my discussion of feminine dyads, but here it is important to describe my initial perception of her gender display. The blonde woman's exercise clothing was tight fitting, revealing her form, and she wore her bleach blonde hair pulled back in a tight pony tail. Bordo (1995) described the characteristics of emphasized femininity as a woman's attempts to remain "slim, childlike, and docile and on the other hand to convey an attitude of constant sexual readiness and appetite". This woman's tight clothing suggested an attempt to gain masculine cultural capital through her adherence to an emphasized feminine display. One day this blonde woman sat with a middle aged man and as opposed to the first time I saw her, she wore no makeup, creating a noticeable difference in her youthful appearance. She was wearing exercise clothes like before, but now she wore loose pants instead of her previous tighter fitting pair. The man sitting at the table with her was constantly looking at his smartphone, and even when she spoke to him his eyes rarely left the screen. His display of inattentiveness appeared consistent with a display of hegemonic masculinity, as masculine dominance is often maintained through devaluing the feminine (Pascoe 2011). Although she used lots of hand gestures and an assertive speaking style, leaning forward across the table, the man sat sideways, facing away from her, and rarely responded to her using only a few words or mild laughter. Her gender maneuvering strategy of an assertive conversational style and an emphasized feminine display seemed to have little commanding effect in this dyadic transaction. Her continued adherence to the physical ideals of emphasized femininity may have only served to reify this man's hegemonic display of masculinity. Her companion's devaluation of her social status through inattention appeared to inhibit her ability to gain any masculine cultural capital.

In my second observation of the blonde woman taking part in a mixed-gender dyadic transaction, she was wearing more makeup than usual and was dressed in a turquoise hoodie highlighting her blonde hair, which appeared much shorter than before. She was seated close to a man at another table who was different from her previous companion. He was dressed in a working class fashion with a tan hat and short, neat hair. This man sat facing her as she talked in her typical assertive manner, and he appeared to pay close attention to her, constantly making eye contact. She stood up once and struck a self-defensive pose, appearing to demonstrate a defensive maneuver and the man smiled and applauded her. After 20 more minutes of chatting the woman said it was "very nice" to meet him and then left the store with a huge smile on her face. Although she still maintained her emphasized feminine appearance, her assertive conversational style and self-defensive demonstration suggested that she was performing gender maneuvering by temporarily adopting masculine traits to gain power in this social transaction. She appeared to have the agency to utilize both emphasized femininity and traits of hegemonic masculinity simultaneously, allowing her to gain dominance in this dyad.

One final example of gender maneuvering appeared in the dynamic interactions of a middle aged white couple. The couple entered the store one morning, ordered drinks, and then the man paid for the drinks and brought them to their table. He handed the woman her drink before sitting down and apologized that it took so long. The man then made several phone calls trying to purchase tickets for a concert for him and a "buddy". The woman stated loudly while he was still on the phone that he "never ask[s] [her] to go to concerts" with him and he responded that he wasn't sure he would get the tickets. The woman sat quietly, doing something on her smartphone, while the man spoke to someone about the tickets and she corrected his speech often, making his face turn red. When he finished the woman said "see I told you, you could take care of that" and he responded "yes, you were right". The woman read a newspaper and told the man about many of the politically charged headlines. The man responded to each viewpoint, always affirming what she said, never seeming to disagree. Eventually she started talking negatively about a city official and he disagreed with her. She immediately asked in a very loud voice "are you arguing 
with me?" After five minutes of attempting to explain his point of view the woman stated "I'm done here" and stood up, heading to the door. The man jumped up and followed close behind her, looking concerned. The female in this dyad appeared to display more characteristics of a masculine gender expression than the male did, thus allowing her to access a greater amount of masculine cultural capital, giving her power within the dyad. She was very assertive in making her demands of him and even hostile at times in her speech and tone of voice. Her companion engaged in a submissive role, deferring to her aggressive and dominant display of social power. Yet her behavior was also contradictory. She did not offer to pay for her own drink or wait to pick it up, but expected her companion to provide for her, as well as expecting him to take her out to a concert. This behavior suggests a desire to be treated as the heterosexual companion to a dominant masculine social actor, fulfilling the normative provider/homemaker partnership ideal. However, through her gender maneuvering practice of dominating her dyad's transactions, she may in fact have hindered her ability to get the treatment she demanded, by not allowing her companion to fully enact the masculine role of provider. Her strong display of hegemony in the dyad appeared to undermine the emphasized feminine treatment she simultaneously expected.

\section{GENDER MANEUVERING IN FEMININE DYADS}

In dyadic transactions where the gender display of both participants is normatively feminine, either individual may display behaviors commonly ascribed to hegemonic masculinity in order to gain masculine cultural capital and achieve a dominant position. When cultural capital is gained through such a display it can increase the individual's social power, asserting their control over the allocation of resources within that dyad. My observations suggest that women occasionally appeared to perform such gender maneuvering strategies while having coffee with other women, and that their access to masculine cultural capital similarly increased.

As previously stated, my first encounter with the blonde woman was as part of a small group. There was a young man who sat with her and another woman, but as he spent all of his time working on his laptop, I was able observe purely dyadic interactions between the two women. Both of these women were dressed in exercise clothing, yet the blonde woman's clothing was tight fitting and the other female wore baggier clothing that hid her stockier figure. They both appeared to be dressed in a normative feminine fashion, although the blonde woman's appearance was more in line with the youthful ideals of emphasized femininity. The blonde woman's tighter clothing suggested an attempt to gain masculine cultural capital through her adherence to an emphasized feminine display, an endeavor which her female companion did not share; potentially giving the blonde woman a privileged position over her in the eyes of masculine social actors who might view her as a more desirable heterosexual partner. The blonde woman also spoke animatedly, smiling and using hand gestures, whereas her companion spoke with a quieter voice. The blonde woman thus appeared to dominate the conversation through an assertive speaking style, behavior typically ascribed to masculine social actors, thus furthering her gender maneuvering efforts to gain dominance in this dyadic transaction. The blonde woman and her friend returned during my second week of observations. They appeared much less animated in their conversation than before, and seemed to be having a serious talk as neither of them smiled and the second woman often wiped tears from her eyes. After a while they started to talk in a more animated fashion and smiles appeared. The blonde woman sat taller and straighter than her companion, and spoke more often and in a louder voice. The other woman sat with a hunched posture and only spoke when the blonde woman had finished talking. Through her straighter posture, command of the conversation, and stricter adherence to emphasized femininity, the blonde woman performed gender maneuvering through her dual gender displays and appeared to assert a position of dominance within this dyad.

Another excellent example of a female dyad performing gender maneuvering strategies through displays of both hegemonic masculinity and emphasized femininity, came in the form of a young same-gendered couple who entered the store holding hands one day. This was the only time I observed a same-gender romantic dyad come into Coffee Corps, which was surprising, as this neighborhood contains many music venues and thrift stores where I regularly observe and interact with members of the LGBTQ community. This unique dyad's gender display was that of a heteronormative mixed-gendered couple. The feminine presenting individual was dressed in pants and a colorful wool jacket and she wore her bleach blonde hair long and straight. The masculine presenting individual was wearing jeans, a studded belt, and a button up Dickies shirt underneath 
an athletic jacket. They also had a curvy feminine figure, with ample hips and breasts, and wore their hair cropped very short and dyed burgundy. They also had many piercings in their lip, nose, and ears, a tattoo on the side of their neck, and they did not appear to wear any makeup. The couple ordered drinks at the counter and the masculine presenting individual paid for them. After getting the drinks they left the store and the masculine presenting individual rushed ahead to hold the door open for the feminine presenting individual. The masculine presenting individual performed the heteronormative rituals of paying for drinks and holding the door, while the feminine presenting individual appeared to accept these gestures in the typical feminine role. Within the context of this same-gendered female couple, one individual adopted the traits of hegemonic masculinity, affirming their status as the masculine social actor. The other woman performed the rituals of emphasized femininity, waiting for the door to be opened for her, and ordering her drink without offering to pay, which potentially reified her companion's position of dominant masculinity. Through a display of hegemonic masculinity, this masculine presenting individual was able to access masculine cultural capital and its associated social power, entitling them to be viewed as a privileged social actor. This dyad's same-gendered composition at first may appear to serve as a challenge to heteronormativity, yet in their engagement with heterosexual dating rituals they may have only served to reify hegemony.

\section{GENDER MANEUVERING IN MASCULINE DYADS}

Although the gender expression allocating the most resources to an individual in our society is hegemonic masculinity, not all male identified individuals have the same access to masculine cultural capital. Stratification often occurs within masculine dyads, where some men perform a gender maneuvering strategy placing them in a deferent role, in order to gain access to cultural capital through the dominant actor in the dyad. This is known as performing a "complicit masculinity", where men benefit from hegemonic masculinity even if they do not use it personally as their gender expression. Or they may perform a "subordinate masculinity", which is relegated to many subordinate group members who suffer under hegemonic masculinity, due to their lack of access to masculine cultural capital (Connell 1995; Pascoe 2011).

One day two men entered the store dressed in business attire; one wearing a suit and tie, the other wearing a slightly more casual outfit and an overcoat. The more professionally dressed man stated that he was paying for their drinks and proceeded to order something fancy, while the other man ordered the cheapest drink on the menu. The first man insisted that the other at least get something to eat, and the second man consented, ordering a bagel. They sat near me and began talking about a non-profit organization that empowers inner-city youth by taking them on fishing trips, and how they would both love to be able to fish for a living. At the end of their conversation the more casually dressed man asked the other man if he could pray with him and "thank God" for the work the other man was doing for the people of this city. In this dyad the more professionally dressed man appeared to display hegemonic masculinity, through his expensive clothing, paying for drinks, and insisting the other man take advantage of his offer. The other man displayed a subordinate, perhaps complicit masculinity, accepting the other man's offer of provision and by showing the other man deference through the honoring act of religious invocation. The first man's hegemonic display implies access to more cultural capital and therefore a dominant status in the dyad. The second man's display of subordinate masculinity exemplifies a type of gender maneuvering described as a shift from the dominance to deference, from masculine toward feminine, allowing the second man to "save face" (Goffman 1955) in the presence of someone displaying a more dominant form of masculinity.

An alternative motivation for gender maneuvering can be understood through the observations I made of a man and his very young son, dressed in a junior-sized New York Yankees tracksuit. The man was reading a book to the boy that had lots of brightly colored pictures, about a father and son who had a misunderstanding and worked together to resolve it. Part of the story seemed to be centered on the son being "good" and "obedient" and the boy repeated these terms excitedly. Another part of the book was about the boy in the story taking care of his little sister, and the man emphasized this part by drawing out the words. More of the story talked about what the little boy could do "all by himself" and a few of the other chores in the story were "helping dad trim a tree" and "ice a cake". It is interesting to note that the young boy was dressed in an athletic track suit, a style typical of "urban" masculinity, often expressed within communities of color that lack the socioeconomic resources to acquire masculine cultural capital (Ocampo 2010). 
However, gender maneuvering occurred here when the father read a story that associated being a "good boy" with taking care of (nurturing) the boy's little sister and participating in domestic labor. This may be an instance of "redoing gender" (Connell 2010) to construct an equalitarian form of masculinity within his son. Whereas most of the gender maneuvering I observed in this study appeared to be attempts to access masculine cultural capital, this instance appeared to an attempt to undermine hegemony and create a concept of masculinity that was not dependent on the subordination of other genders.

\section{GENDER MANEUVERING THROUGH DISPLAYS OF ALTERNATIVE FEMININITY}

Some studies suggest that "redoing gender" through revisions to gender accountability "weaken its utility as a grounds for men's hegemony" (West and Zimmerman 2009; Connell 2010). Redoing gender through forms of alternative femininity (Schippers 2002) may act to challenge the hegemonic gender binary through displays that do not bolster masculine dominance. Some of these alternative femininities may appear as genuine challenges, while others may actually tend to maintain the status quo through the feminizing or accessorizing of expressions that once sought to be more independent of masculinity and hegemony. The following examples of gender maneuvering were observed in the relatively brief transactions that occurred within dyads composed of two strangers; a customer and the barista. Although these dyadic transactions deviate from the previous observations of what we might call coffee dates, these displays of alternative femininity suggest methods of gender maneuvering that have the potential to subvert hegemony if they can avoid succumbing to complicity with it.

During one of my last observational periods, the blonde woman entered the store alone wearing black jeans and a men's plaid, long-sleeved shirt. Her hair appeared a bit messy, as if she hadn't brushed it, and she wasn't wearing any makeup. Her gender expression seemed to have changed from emphasized femininity to more of a "gender-blender" style (Moore 2011). She also appeared to be less physically fit than my initial observations and her gender display did not seem to adhere to the standards of emphasized femininity as much as it did at first, potentially detracting from her previous gender maneuvering strategy. This new gender display could have been a shift in her overall gender expression and a challenge to the hegemonic binary. Yet by distancing herself from the feminine to access masculine cultural capital, her gender display might actually emulate a complicit masculinity (Pascoe 2011, 182). However, in failing to perform an emphasized feminine display, she did not adhere to the status quo and therefore appeared to accessing masculine cultural capital by displaying an alternative femininity.

More subtle displays of alternative femininity can be described by my last set of customer observations. Several women came through the store that all had a very similar style and appeared to display a similar form of alternative femininity. The first was a younger woman with very long blonde hair worn loosely down her back. She wore extra-high heels, black lacey tights, and the hem of a black dress could be seen hanging below a long black leather overcoat. She wore large designer sunglasses high on her head and carried a large black leather purse. Her makeup was very vivid; her face a uniform pale white, her lips a deep purple-red, and her eyes heavily accented with a black rockabilly "cat eye" style. This woman's gender presentation appeared very feminine, with tight fitting clothing that accentuated her shape. Yet her makeup suggested more of a rockabilly gender expression, communicating a sense of confidence, power, and danger (Finely 2010) and her sharp tone of voice and lack of facial expression implied the possession of masculine cultural capital. However, this performance of alternative femininity appeared to feminize the rockabilly style more than its originators may have intended. She in fact seemed to adhere to emphasized femininity through most of her clothing choices, while her social interactions and rockabilly makeup suggested rebellion against hegemonic ideals.

The other two woman displayed minimalist versions of a Punk Girl style, while their overall gender displays appeared to be that of emphasized femininity. The first was a younger woman wearing black leggings and a black leather jacket. Her hair was dyed black and worn straight and long and she wore kneehigh brown leather boots and carried a black leather purse. The purse had black fringe dangling off the bottom and was lined with a thin row of gold studs. She also partially covered her hair with a black beanie cap and wore deep red lipstick with lots of cover-up. This woman had an overall gender display similar to the other woman's emphasized femininity; however, the Punk Girl fashion accessories (the studs, makeup, and beanie) were utilized with no threat toward her social status or the typical 
social sanctioning directed at being a punk. Her low-cut V-neck shirt and black leggings embodied current trends in fashion that attempt to accentuate the female figure, thus she appeared to maneuver between emphasized femininity and the alternative Punk Girl gender display.

The other woman entered the store wearing a leather jacket, a long gray blouse, black leggings, and short suede boots with gold studs on them. She also had a large leather purse with studs on it, large dark sunglasses, and platinum blonde hair. This woman appeared to be middle-aged and in very good shape. She received her coffee quickly and left the store without smiling or returning any of the friendly social gestures made by the female barista. This woman's gender presentation, with the accessorizing of studs, platinum hair, and emphasized makeup, also suggest a Punk Girl form of alternative femininity, yet accessorized in an emphasized feminine way. The studs on her boots were golden, as were the studs on her oversized purse, and the boots themselves were platform high heels. Her flat affect and distant attitude were also indicative of a gender maneuvering strategy of devaluation similar to traits of hegemonic masculinity.

For women who may display an overall rockabilly or Punk Girl self-expression, there may be social sanctions associated with performing such non-compliant gender displays. However, for these middle-class women there seemed to be no such dangers involved in wearing cat eye makeup, accessorizing with a few studs or fringe, and wearing feminized leather garb. Although their overall gender display is that of emphasized femininity, these women appear to be accessing masculine cultural capital by maneuvering between their primary gender displays and alternative femininities. They may receive positive feedback from hegemonic masculinity for embodying the ideal heterosexual partner to a dominant male, and yet their rockabilly and punk accessories also grant them some access to alternative femininity's defiant stance against hegemony. The contradiction here lays in the fact that while displaying alternative femininity in an accessorized manner may allow them to bolster their access to masculine cultural capital; they in fact tend to reify hegemonic dominance through their complicity with emphasized feminine ideals, serving to undermine the true spirit of alternative femininity.

\section{DISCUSSION}

During my observations the patrons of Coffee Corps often appeared to do gender by temporarily performing displays of hegemonic masculinity; and many times these gendered transactions did not align with their primary gender displays. These individuals deviated from the heteronormative binary by employing gender maneuvering strategies to gain masculine cultural capital; either by temporarily utilizing traits of hegemonic masculinity, or through displays of emphasized or alternative femininities. In many of the mixed-gendered and same-gendered dyads observed there appeared to be a gender binary being played out in ways often contrary to heteronormative practices. This was the most obvious and intriguing aspect of doing gender that I observed during my visits. I found that some women temporarily displayed traits of hegemonic masculinity in order to secure a dominant interactional position over another female or a male; and that both women and men displayed traits of emphasized femininity in order to gain access to cultural capital through deference to a dominant, masculine social actor. I also found that several of the patrons frequenting the shop expressed femininity through alternative gender displays in their interactions with baristas. These 
alternative displays appeared to be an attempt to undermine hegemonic ideals of feminine behavior; however, they may in fact have served to reify the gender binary through feminizing and accessorizing subculture identities. I observed dyadic, gendered transactions through individual's conversational styles and gender displays, allowing me to identify and analyze their unique gender maneuvering strategies. My observation of gender display variations informed the analysis of specific gender maneuvering strategies and the impact of such tactics on the acquisition of masculine cultural capital.

The results of this study serve to explain how individuals on coffee dates or interacting with baristas attempted to redo the gender binary power structure; in order to increase their social power and to acquire resources typically reserved for those displaying hegemonic masculinity. These results should add to the implications of doing gender theory, in that the construction and performance of a gender display is often situational and readily maneuvered to serve the interests of an individual seeking to access masculine cultural capital. Therefore the heteronormative binary and its inherent inequalities may be routinely subverted through gender maneuvering strategies, to redo gender along more equitable lines. However, the findings of this study suggest that most individuals fail to undermine hegemony and instead typically reify masculine dominance by performing and thereby legitimizing oppressive social behaviors. When individuals are able to adopt traits (such as assertiveness) ascribed to masculinity without engaging in hegemonic complicity; individuals may succeed in redefining those traits as gender-neutral, and gain access to desired resources without placing the other member of their dyad in a subordinate role. The father reading his son a book with equalitarian ideals came closer than any other patrons I observed in attempting to redo gender and undermine hegemony.

However, most of the gender displays I observed during this study appeared to only reify hegemony's masculine dominance, instead of challenging it in true form. Women who temporarily employed traits of hegemonic masculinity endorsed those behaviors as a legitimate means for gaining social power and dominance, reifying hegemony instead of creating more egalitarian interactional norms. Women and men displaying the deferent traits of emphasized femininity to gain access to resources through a dominant masculine actor also serve to legitimize hegemony. Women in this study who had the ability to perform gender maneuvering strategies could be said to have agency in acquiring the power to improve their social position, granting them access to social resources and privilege. However, in the long-term any agency acquired through the hegemonic system will only legitimize social institutions that operate on gender inequality; thus these women's agency may be a farce. What I failed to observe, the equitable allocation of resources within dyads, may be indicative of the context of this particular organizational setting. The heteronormativity of the coffee date establishes a framework for gender maneuvering strategies, granting individual agency only when individuals are complicit in the reification of a hegemonic gender binary. To truly undermine hegemony it seems that alternative displays of femininity and masculinity must subvert the ideals of hegemony, while carefully avoiding any actions that might serve to reify it. Future research might consider organizational settings in which gender maneuvering occurs without the reification of hegemony; where alternative gender displays seek to dismantle the gender binary and replace it with a spectrum of genders founded in equality. Future research could also include interview and survey data to identify individual self-concepts of gender displays and to better understand individual reasons for specific gender maneuvering strategies. Subordinated genders who enact displays of hegemonic masculinity only serve to legitimize gender inequality. Thus research into the outcomes of alternative gender maneuvering strategies could function to create more equitable dyadic transactions, where gender ceases to serve as a primary determinate in the allocation of power and resources in society. In order to redo gender in organizational settings like Coffee Corps, individual actors must diverge from hegemony and embrace gender equality. 


\section{REFERENCES}

Becker, Howard, and Ruth Hill Useem. 1942. "Sociological Analysis of the Dyad." American Sociological Review 7(1): 13-26.

Bordo, Susan. 1995. Unbearable Weight: Feminism, Western Culture, and the Body. Berkeley: University of California Press.

Bourdieu, Pierre. 1984. Distinction: A Social Critique on the Judgment of Taste. Cambridge: Harvard University Press.

Connell, Catherine. 2010. “Doing, Undoing, or Redoing Gender? Learning from the Workplace Experiences of Transpeople." Gender \& Society 24(1): 31-55.

Connell, Raewyn W. 1987. Gender and Power: Society, the Person, and Sexual Politics. Stanford: Stanford University Press Pages.

Connell, Raewyn W. 1995. Masculinities. Berkeley: University of California Press.

Emerson, Robert M., Rachel I. Fretz, and Linda L. Shaw. 2011. Writing Ethnographic Fieldnotes. Chicago: University of Chicago Press.

Finley, Nancy J. 2010. “Skating femininity: Gender Maneuvering in Women's Roller Derby." Journal of Contemporary Ethnography 39(4): 359-387.

Goffman, Erving. 1955. “On Face-Work: An Analysis of Ritual Elements in Social Interaction." Journal for the Study of Interpersonal Processes 18: 213-231.

Goffman, Erving. 1976. "Gender Display." Studies in the Anthropology of Visual Communication 3: 69-77.

Lodge, Amy C., and Debra Umberson. 2012. “All Shook Up: Sexuality of Mid-to Later Life Married Couples." Journal of Marriage and Family 74(3): 428-443.

Moore, Mignon. 2011. Invisible families: Gay Identities, Relationships, and Motherhood Among Black Women. Berkeley: University of California Press.

Ocampo, Anthony C. 2012. “Making Masculinity: Negotiations of Gender Presentation Among Latino Gay Men." Latino Studies 10(4): 448-472.

Pascoe, C.J. 2011. Dude, You're a Fag: Masculinity and Sexuality in High School, With a New Preface. Berkeley: University of California Press.

This work is licensed under a Creative Commons AttributionNonCommercial-

NoDerivs 3.0

Unported License. 
Schippers, Mimi. 2002. Rockin' Out of the Box: Gender Maneuvering in Alternative Hard Rock. Newark: Rutgers University Press.

Schippers, Mimi. 2007. “Recovering the Feminine Other: Masculinity, Femininity, and Gender Hegemony." Theory and Society 36(1): 85-102.

West, Candace and Don Zimmerman. 1987. “Doing Gender." Gender and Society 1(2): 125-151.

West, Candace and Don Zimmerman. 2009. "Accounting for Doing Gender." Gender and Society 23(1): $11-122$.

Wood, Julia T. 2000. Gendered Lives: Communication, Gender, and Culture. Belmont: Wadsworth. 